CRÍTICA, Revista Hispanoamericana de Filosofía

Vol. XXX, No. 88 (abril 1998): 29-48

\title{
THE CONSTITUTIVE IDEAL OF RATIONALITY: DAVIDSON AND SELLARS
}

\author{
JoHn McDoweLL \\ University of Pittsburgh
}

The nomological irreducibility of the mental does not derive merely from the seamless nature of the world of thought, preference, and intention, for such interdependence is common to physical theory, and is compatible with there being a single right way of interpreting a man's attitudes without relativization to a scheme of translation. Nor is the irreducibility due simply to the possibility of many equally eligible schemes, for this is compatible with an arbitrary choice of one scheme relative to which assignments of mental traits are made. The point is rather that when we use the concepts of belief, desire, and the rest, we must stand prepared, as the evidence accumulates, to adjust our theory in the light of considerations of overall cogency: the constitutive ideal of rationality partly controls each phase in the evolution of what must be an evolving theory. An arbitrary choice of translation scheme would preclude such opportunistic tempering of theory; put differently, a right arbitrary choice of a translation manual would be of a manual acceptable in the light of all possible evidence, and this is a choice we cannot make. We must conclude, I think, that nomological slack between the mental and the physical is essential as long as we conceive of man as a rational animal. ${ }^{1}$

1 Donald Davidson, "Mental Events", in his Essays on Actions and Events, Clarendon Press, Oxford, 1980, pp. 207-225; this quotation is from pp. 222-223. 
Richard Rorty has recently ${ }^{2}$ aimed to represent the ideas expressed in this familiar passage as an aberration, something that could be removed while leaving the basic thrust of Davidson's philosophy undamaged and indeed purified. I have some reservations about some of the detail of the passage, but I think, against Rorty, that its basic claim - that an ideal of rationality is constitutive of the very idea of the mental, and that that ensures a special irreducibility of concepts of the mental to concepts of the natural sciences and their kin in everyday thought and speech - is central to an authentically Davidsonian philosophy. To begin on urging that Rorty's suspicions are misplaced, I am going to juxtapose the Davidsonian irreducibility claim with a parallel claim made by another great twentieth-century North American philosopher, and another of Rorty's heroes, Wilfrid Sellars - a claim expressed by Sellars in passages that, it seems to me, Rorty bowdlerizes, in a way that fits with his distaste for this and similar passages in Davidson.

The point Davidson makes in this passage relates to the constitutive role of rationality in our thought and talk of the mental in general. In the second part of this paper, I want to consider an aspect of how the point applies to the semantical in particular - the characteristics of our linguistic repertoires that enable us to give expression to our mental states, as we might say in order to bring out the connection between the semantical and the explicit topic of that passage from "Mental Events". Here too I shall exploit Sellars, this time not as thinking in parallel with Davidson, but as subject to a blind spot concerning a feature of Tarskian semantics about which Davidson is completely clear. The blind spot persists, I think, into Rorty's

${ }^{2}$ For instance in a comment forthcoming in a symposium on my Mind and World, Harvard University Press, Cambridge, Mass., 1994, to appear in Philosophy and Phenomenological Research. 
attempt to appropriate Davidson for his own purposes, and it vitiates Rorty's reading of Davidsonian semantics.

\section{I}

First, then, an echo of the Davidsonian irreducibility thesis in Sellars. Where Davidson says that our thought and talk of the mental is governed by a constitutive ideal of rationality, and that this ensures that its concepts cannot be reduced to concepts that figure in ways of thinking and talking that are not so governed, Sellars says that our thought and talk of the epistemic needs to be understood as functioning in the logical space of reasons, and that this ensures that concepts of the epistemic cannot be understood in terms of concepts that do not so function. ${ }^{3}$ It seems irresistible to suppose that the logical space of reasons, in Sellars, plays a role that corresponds to the role of the constitutive ideal of rationality, in Davidson.

When Sellars's thought is put, as I have just put it and as Sellars sometimes does, in terms of the epistemic, it can seem that it relates exclusively to knowledge, so that Sellars's irreducibility claim has a different topic from Davidson's. This appearance enables Rorty to thin down Sellars's thought into the idea that the acceptability of knowledge claims - the supposed exclusive target of Sellars's remarks about the logical space of reasons - is a matter of "victory in argument". 4 Thus Rorty can suggest that the point is to discourage the idea that knowing is a factual feature of a person irreducible, in a way that risks

${ }^{3}$ See "Empiricism and the Philosophy of Mind", in Herbert Feigl and Michael Scriven (eds.), Minnesota Studies in the Philosophy of Science, vol. 1, University of Minnesota Press, Minneapolis, 1956, pp. 253-329; see especially pp. 298-299.

4 Philosophy and the Mirror of Nature, Blackwell, Oxford, 1980, p. 156. 
looking mysterious, to what can be truly said about her in naturalistic terms, let alone that mindedness is such a feature, by registering that victory in argument cannot be had without actually arguing; who wins an argument is not, for instance, predictable by exploiting a theory in some special science.

I think this is a misreading. Sellars exploits attributions of knowledge only as a particularly clear case for the point he wants to make. In fact he uses "epistemic" as a term of art, covering far more than what the word's etymology would suggest. For instance, he counts something's looking red as an epistemic fact about the thing, as opposed to a natural fact. ${ }^{5}$ ("Natural" is his way of gesturing towards the concepts to which concepts of the epistemic cannot be reduced, as we are to appreciate by seeing that concepts of the epistemic function in the logical space of reasons.) And at one point he writes, strikingly, of "the epistemic character, the intentionality" of expressions such as "thinking of a celestial city. ${ }^{6}$ Here it is even clearer that the word "epistemic" comes loose from its etymology. I think this example shows that the epistemic, for Sellars, covers states or episodes that involve the actualization of conceptual capacities and as such have intentionality or objective purport, whether or not they amount to cases of knowledge. This makes the irreducibility thesis that Sellars underwrites by invoking the logical space of reasons a pretty exact match for the irreducibility thesis that Davidson underwrites by invoking the constitutive ideal of rationality. A thesis that applies to thinking of a celestial city cannot be captured by Rorty's appeal to victory in argument. Sellars's thought is a version of the irreducibility claim that Rorty wishes Davidson had not embraced.

5 "Empiricism and the Philosophy of Mind", p. 274.

6 Ibid., p. 260. 
There is a precedent for Sellars's using "epistemic" in this at first sight strange way, so that it matches the way Davidson uses "mental" in "Mental Events". The precedent I mean is Kant's first Critique. From the language of that work, one might think knowledge is its primary concern. But in fact Kant's concern is not knowledge so much as the directedness of thought at objects, the intentionality or objective purport, that is a prerequisite for anything to be even a candidate to be a case of knowledge. Heidegger says: "The Critique of Pure Reason has nothing to do with a "theory of knowledge" "? That is surely excessive, but in its over-the-top way it points towards a claim that would be correct, and one that could also be correctly made about Sellars's "Empiricism and the Philosophy of Mind".

Of course the presence in Sellars of a thesis to the effect that the intentional or the conceptual has a special irreducibility, matching the special irreducibility Davidson attributes to the mental, does not by itself address Rorty's wish that there were no such thing in Davidson. If I am right that the same thought is in Sellars, Rorty will simply include Sellars in the wish that it were not so. We need to consider the grounds for the wish.

So why does Rorty deplore the irreducibility thesis? The answer is: he fears that it merely encourages philosophy in a certain traditional vein - philosophy of a sort that he is surely right to think Davidson, like Rorty himself, wants to display as superfluous, rather than something that responsible intellectuals have an obligation to go in for. Davidson urges that concepts of the mental are irreducible to concepts of the natural sciences in a special way, to be traced not simply to the fact that talk and thought of

7 Kant and the Problem of Metaphysics, translated by Richard Taft, Indiana University Press, Bloomington and Indianapolis, 1990, p. 11. Heidegger's word is "Erkenntnistheorie", which might have been translated "epistemology"; see Taft's note, p. 188. 
the mental hang together holistically — as perhaps talk and thought of, say, the biological do also - but to the need to invoke rationality in characterizing this as a particular and special instance of holistic interconnection. The point turns not on holism as such but on a special holism, in which the elements hang together in a way that can be captured only by invoking an ideal of rationality. Rorty's fear is that when Davidson thus singles out concepts of the mental as subject to a special irreducibility, that encourages a familiar sort of philosophical mind-boggling at how peculiar the mental is, and a familiar sort of philosophical project in which we take ourselves to have to tell supra-empirical stories to re-establish connections to ordinary reality for minds, conceived thus as peculiar and concomitantly as separated from ordinary reality. Within this sort of project, it will seem that we need to choose among the standard options for dealing with "the mind-body problem" and "the problem of knowledge", thus engaging in the kind of traditional philosophical activity whose unsatisfactoriness Rorty is so good at bringing out. Rorty cannot see how the thesis of a special irreducibility can do anything but undermine a purpose he and Davidson share, to dissolve the appearance that we are intellectually obliged to go in for that sort of activity. The shared purpose is, for instance, that we should entitle ourselves to "tell the skeptic to get lost", rather than look for a way to answer him. ${ }^{8}$

I think this is exactly wrong. The idea of a special irreducibility, which I am representing as common to Davidson and Sellars, is precisely a condition of properly understanding how it comes to seem that the mental poses that kind of problem for philosophy, and thereby a condition of

${ }^{8}$ Compare Davidson's afterthought to "A Coherence Theory of Truth and Knowledge", in Alan Malachowski (ed.), Reading Rorty, Blackwell, Oxford, 1990. 
achieving the very goal that Rorty thinks the idea threatens: seeing through the potentially gripping illusion that we need to acknowledge and deal with problems of that kind.

The separation of logical spaces or constitutive ideals that underwrites the irreducibility thesis reflects a distinction between two ways of finding things intelligible. Both involve placing things in a pattern. But in one case the pattern is constituted by regularities according to which phenomena of the relevant kind unfold; in the other it is the pattern of a life led by an agent who can shape her action and thought in the light of an ideal of rationality. In the modern era a distinction on these lines acquired a deep cultural significance, with the first kind of understanding, as contrasted with the second, coming to be seen as the business of natural science - a pursuit that achieved intellectual maturity in part precisely by virtue of having the kind of understanding that is its proper goal increasingly sharply separated from the kind exemplified by seeing a phenomenon as an agent's attempt to live up to an ideal, so that, for instance, it no longer counted as science to read nature as a meaningful text. While this kind of significance was attaching itself to the distinction between the two sorts of understanding, there will have been an increasingly sharp sense of a specialness on the part of concepts whose functioning is bound up with finding things intelligible in the second way, the way that involves conceiving of human beings as rational animals (to echo the passage I quoted from "Mental Events"). This is the sense of specialness that Davidson and Sellars formulate in the theses that disturb Rorty, and so far it is, I think, an innocuous recapitulation of something that was essential to the maturing of modern natural science.

However, at a primitive stage in the intellectual and cultural development I am talking about, it would be natural that there should be an attempt to accommodate this spe- 
cialness, as yet only vaguely sensed, by trying to conceive the subject matter of thought and speech about the mental as a special region of what was, at the stage I mean to be considering, only beginning to come clear as the proper subject matter of the natural sciences - the disciplines whose business is in fact the other kind of understanding. This is a recipe for making sense of Cartesian philosophy of mind, at least on the more or less Rylean reading under which Descartes figures in the standard contemporary picture of how philosophy of mind developed. On this reading, Descartes confusedly wanted the relations that organize the mental to be just special cases of the sorts of relations that organize the proper subject matter of the natural sciencesrelations that are displayed when phenomena are captured by descriptions suited for subsuming them under laws. But the specialness of the mental, to which on this reading Descartes was responding without a proper comprehension of its basis, requires those relations, supposedly suitable for natural-scientific treatment, to do duty for the relations that constitute the space of reasons. That is why Cartesian thinking takes a form to which Ryle's term of criticism "para-mechanical" is appropriate. Cartesian immaterialism is intelligible within the framework I am describing; no part of material nature could be special enough to serve the essentially confused purposes of this way of thinking. If one tries to make connections of the sort that figure in descriptions of law-governed processes do duty for relations of justification or warrant, one will naturally lapse into an appeal to magic, masquerading as the science of a weird subject matter; what one intends to postulate as simply mechanisms, though of a special kind, will degenerate into what Ryle lampoons as para-mechanisms.

On this account, the Cartesian Real Distinction, which is the point of origin of the supposed "mind-body problem", reflects a confused attempt to make a distinction within 
the subject matter for natural science - a distinction that inevitably degenerates into pseudo-science on one of its sides - out of the differentiation of batteries of concepts that is common to Davidson and Sellars, which is in fact not that kind of distinction at all. The puzzlements of traditional epistemology have the same source. Understanding the illusory obligations of traditional philosophy, which includes appreciating how the illusion can be gripping, requires that we understand the temptation to fall into this confusion. Hence it exactly requires that we do not discard the distinction of batteries of concepts that bothers Rorty, but rather that we understand it correctly, seeing through the temptation to misconceive it in the Cartesian way.

I said that I have reservations about some of the detail of the passage I quoted from "Mental Events", and I shall end this first part of my paper by connecting one of them with the way I have been formulating its basic claim. I have been expressing the point of invoking the constitutive ideal of rationality by talking in terms of a distinctive way of finding things intelligible: seeing them as part of the life of an agent concerned to live up to an ideal of rationality. I have not connected the point, as Davidson does, with Quine's thesis of the indeterminacy of translation. Some of the resonances of that way of pointing to what underwrites the irreducibility strike me as unfortunate. In particular, if the appeal to indeterminacy imports Quine's thesis that there is no fact of the matter concerning correct interpretation, it risks leaving the impression that the claim is that the mental is non-factual, or at least less factual than what it is contrasted with; as if we were to suppose that on the one hand there is finding out how things are, and on the other hand there is making sense of people. I think making sense of people is a case of finding out how things are - a case that is special, in ways that Davidson has shown us how to understand without letting it seduce us into philos- 
ophy in the Cartesian vein, but a case for all that. Denying that, as we certainly seem to if we accept that there is no fact of the matter, is merely an extreme move in the kind of philosophy that lets its agenda be set by Cartesian conceptions; that is, precisely the kind of philosophy from which Davidson's thought, properly seen, promises to help us liberate ourselves.

\section{II}

I have been considering the Davidsonian thesis that making sense of people, in general, is governed by the constitutive ideal of rationality. I now want to consider an issue that arises when we apply the thesis to making sense of what people say, in particular.

According to Rorty, the results of interpreting linguistic behaviour as Davidson conceives that activity, formulated in theories of truth in the style of Tarski, are "descriptive", and as such not just to be distinguished from, but not even combinable in a unified discourse with, any way of talking in which "true" expresses a norm for inquiry and claimmaking. In particular, truth in a sense that can be glossed in terms of disquotability, which is that whose conditions of application to the sentences of this or that language Tarski showed how to pin down in the kind of theory Davidson adapts to his purposes (provided that we can find a suitable logical form in, or impose a suitable logical form on, the sentences of the language), must, according to Rorty, be held separate from truth as a norm for inquiry. ${ }^{9}$

I think this makes no sense of the obvious connection between, on the one hand, the familiar T-sentences of Tarskian theories and, on the other, such truisms as this: what makes it correct among speakers of English to

${ }^{9}$ See "Pragmatism, Davidson and Truth", in Rorty's Objectivity, Relativism, and Truth, Cambridge University Press, Cambridge, 1991. 
make a claim with, say, the words "Snow is white" (to stay with a well-worn example) is that snow is indeed white. I stress "correct": truth in the sense of disquotability — what Tarskian theories of truth are theories of - is unproblematically normative for the practice of using the sentences mentioned on the left-hand sides of T-sentences in order to make assertions. It does not take much inquiry to entitle oneself to make the particular assertion that I have picked as an example, but the point obviously carries over: truth in the sense of disquotability is a norm for inquiry, just because it is a norm for the claim-making that inquiry aims at. The force of this norm is part of the demandingness of the constitutive ideal of rationality. Rorty's attempt to separate Tarskian theory from such a norm cannot be sustained.

I surmise that this aspect of how Rorty reads Davidson traces back to a doctrine of Sellars about the very idea of the semantical. In discussing this, I shall no longer be drawing a parallel between Sellars and Davidson, but rather setting Sellars in a contrast with Davidson that is to Sellars's disadvantage. The relevant Sellarsian doctrine is that there are no semantical or meaning-involving relations between, as he puts it, elements in the linguistic order or the conceptual order, on the one side, and elements in the real order, on the other. Sellars holds, indeed, that this "non-relational character of "meaning' and 'aboutness" " is "the key to a correct understanding of the place of mind in nature". 10

How can Sellars hold that meaning and aboutness are, flatly, non-relational? Consider, say, a statement of what some expression stands for, say " 'Londres' stands for London". It certainly looks as if that affirms a relation, be-

10 Science and Metaphysics, Routledge and Kegan Paul, London, 1967, p. ix. 
tween a name and a city. But according to Sellars, if such a statement is indeed of semantical import, the expression that figures on its right-hand side is not used, or at any rate not used in the ordinary way, namely to mention a city - as it would need to be for the statement to affirm a relation between the mentioned expression and the city. Rather, the expression serves to exhibit its own proprietygoverned use. If we were to state the relevant proprieties, we would be saying that there ought to be certain relations between, on the one hand, utterances of the expression, considered as elements in the real order, and, on the other hand, other elements in the real order, most notably in this case a city. A relatedness to extra-linguistic reality is normatively required of ordinary utterances of the expression that figures on the right-hand side of a statement of meaning. By virtue of the non-ordinary use to which the expression is put there, the substance of that required relatedness to extra-linguistic reality is reflected into what the statement says about the expression mentioned on its left-hand side, even though it relates that expression only to another expression. That is how Sellars thinks a statement that affirms a relation only within the linguistic order can nevertheless capture the contribution made by the expression mentioned on its left-hand side to the intentional character, the directedness at the extra-linguistic order, of linguistic acts in which the expression figures.

Sellars's conviction that we must thus explain away the appearance that semantics deals with relations reflects, I believe, a failure to see the point of Tarskian semantics. He sometimes discusses Tarskian semantics, but he never, so far as I know, engages with the genuine article.

Sometimes he suggests that the very idea of word-world relations as they figure in Tarskian semantics is "Augustinian", in the sense that fits the opening sections of Wittgen- 
stein's Philosophical Investigations. ${ }^{11}$ But that is simply wrong. It is perfectly congenial to Tarskian semantics to say that the notions of such word-world relations as denotation and satisfaction are intelligible only in terms of how employments of such notions contribute towards specifying the possibilities for "making moves in the languagegame" by uttering whole sentences in which the relevant words occur. These relations between words and elements in the extra-linguistic order should not be conceived as independently available building-blocks out of which we could construct an account of how language enables us to express thoughts at all. Davidson has made this perfectly clear, for instance in "In Defence of Convention T". 12

In other places Sellars suggests that proponents of relational semantics conceive the word-world relations that they take semantical statements to affirm in terms of "ideal semantical uniformities". ${ }^{13}$ This is an allusion to those propriety-governed genuine relations, between linguistic acts considered as elements in the real order and other elements in the real order, that figure in his picture as partly constitutive of the non-relational content of statements of meaning. Here Sellars is reading Tarskian semantics in the light of his own understanding of the possibilities. Statements of those "ideal semantical uniformities" — which are not themselves semantical statements - are the closest his view can come to the idea of semantical statements that themselves affirm relations to elements in the real order.

11 See "Empiricism and the Philosophy of Mind", pp. 290-291. Compare Robert Brandom's contemptuous remarks about "a supposed word-world relation of reference", in his Making It Explicit: Reasoning, Representing, and Discursive Commitment, Harvard University Press, Cambridge, Mass., 1994, pp. 323-325.

12 In his Inquiries into Truth and Interpretation, Clarendon Press, Oxford, 1984.

13 See Science and Metaphysics, pp. 86-87, 112. 
So the best Sellars can do in the way of understanding this idea is to suppose that proponents of relational semantics mistakenly think those statements of "ideal semantical uniformities" - which do deal with relations, relations that there ought to be, with elements in the extra-linguistic order among their relata- are semantical statements. He assumes that his opponents are working within a dimly grasped version of his picture, and misconstrue the significance of its elements.

But that is not the point of the idea that statements of, for instance, the form "... stands for _." relate words to objects. Sellars simply does not engage with a proper understanding of that idea, which is on the following lines. First, the expression that figures on the right-hand side of such a statement is used in an ordinary way, not in the peculiar way that figures in Sellars's account of semantical statements; so we can see the statement as itself affirming a relation between the expression mentioned on the left-hand side and whatever element in the real order can be mentioned by a standard use of the expression on the right - for instance a city, in my earlier example. But second, the idea of the relation thus expressed by "stands for" is - to borrow a Sellarsian phrase - itself fraught with "ought", in a way that reflects what ensures that this conception of semantics is not "Augustinian". ${ }^{14}$ We make sense of the very idea of such relations only in terms of how cases of them enter into determining the conditions under which whole sentences are correctly or incorrectly asserted. Here "correctly" and "incorrectly", applied to performances of making claims, indicate the "oughts" with which relations of, say, denotation are fraught. As I said

${ }^{14}$ For "fraught with 'ought"”, see, e.g., "Truth and Correspondence", in Sellars's Science, Perception, and Reality, Routledge and Kegan Paul, London, 1963, p. 212. 
about the norm constituted by truth as disquotability, these "oughts" ultimately reflect the demands of rationality on inquiry and the claim-making that gives expression to its results.

A descendant of this Sellarsian blind spot for Tarski can account for Rorty's getting himself into the impossible position of needing to deny that disquotability is a norm. Rorty knows that the Tarskian "semantics" Davidson adapts to his purposes is nothing if not relational. Sellars would insist that as such it cannot really be semantics, but the point is not just about the word. The Sellarsian blind spot operates in Rorty's reading of Davidson in the form of a thought on these lines: since the Tarskian theories that Davidson envisages certainly deal with relations between elements of the linguistic order and elements of the extra-linguistic order, they cannot be semantical in Sellars's sense; that is, they cannot deal with meaning or aboutness in any sense that is fraught with "ought". This shows up in Rorty's idea that the Tarskian theories Davidson envisages can have nothing to do with truth as a norm for inquiry. But this line of thought inherits the flaw in Sellars's take on Tarski. It misses the fact that "ought" is already built into the very idea of such word-world relations as those expressible, in neo-Tarskian theory, by "... denotes _" (or "... stands for _ ") or "... is satisfied by _". That is a way of putting the point of "In Defence of Convention T". There is no basis for Sellars's thought, still present in Rorty's reading of Davidson, that we have to choose between relationality and normative import.

Sellars has a blind spot for Tarski. Is that the end of the story? I shall mention two ways of putting the blind spot in context. I think they are ways of approaching the superiority, and philosophical fruitfulness, of the way of thinking about the semantical that Davidson, exploiting Tarski, has made available to us. 
First, it has emerged that there are two different ways in which one might construe the idea that our thought of meaning and aboutness is fraught with "ought". Sellars contemplates only one, and it is less satisfactory than the other, which he does not consider. On the TarskianDavidsonian conception the "oughts" in question - the "oughts" that are built into the idea of, say, denotationare not separable from the idea of correctness in assertion. So they are not seen as prior to the very idea of directedness at the world or objective purport. Sellars, by contrast, envisages "oughts" that relate uses of expressions, as happenings in the real order, to other elements in the real order, in statements of proprieties that can be specified independently of anything semantical; these proprieties can then be seen as determinants, from outside the semantical, of the significance of elements in a language or of the aboutness of unexpressed thoughts. He thinks a language must be constituted by "rule-governed uniformities" that "can, in principle, be exhaustively described without the use of meaning statements". 15 This opens the way to the transcendental sociologism that is elaborated by Robert Brandom in his Making It Explicit.

I think once we see that the intuition that meaning and aboutness are "ought"-laden does not require the relevant "oughts" to be pre-semantical, as they are in Sellars's picture, we can see that there is no ground for the idea that linguistic behaviour must be able to be seen as governed by the sort of proprieties Sellars and Brandom envisage, proprieties that can be formulated in non-semantical terms. There is no reason to suppose the directedness of thought and speech at the world must be thus constituted, from outside the semantical, by norms that, though social, are not yet themselves semantical. One might think that if

15 Naturalism and Ontology, Ridgeview, Reseda, 1979, p. 92. 
such formulations are not available, that leaves meaning and aboutness irredeemably spooky. But once we see that the relevant "oughts" can be as it were on the semantic surface, we can take in stride that meaningful speech, and thought directed at the world, are unproblematically part of our lives - as Wittgenstein says, "as much part of our natural history as walking, eating, drinking, playing". ${ }^{16}$

The second approach to Sellars's blind spot for Tarski that I want to exploit is through an argument from Sellars's remarkable paper "Being and Being Known". ${ }^{17}$ The context is a standing Sellarsian thesis, that the aboutness of unexpressed thought is to be understood on the model of the semanticity of speech. In "Being and Being Known" Sellars frames that thesis in terms of a Thomistic conception of intellectual acts as (second) actualizations of intellectual words. This allows him to express the idea that the intentionality of non-overt intellectual acts - mental actsis to be modelled on the semanticity of overt intellectual acts - acts of speech - by representing the intentionality of non-overt intellectual acts as a case of the semanticity of words. The intentionality of a non-overt intellectual act is determined by the semantics of the intellectual words that are actualized in it. And now his blind spot to the possibilities for Tarskian semantics shows up as a blindness to the possibility that the semantics of intellectual words might be captured in Tarskian terms.

This blindness matters for an argument Sellars offers for his doctrine that aboutness is non-relational. The argument works by assuming that the alternative is to suppose that "intellectual acts differ not in their intrinsic character as acts, but by virtue of being directly related to different

16 Philosophical Investigations, Blackwell, Oxford, 1951, §25.

17 In Science, Perception, and Reality, pp. 41-59. 
relata". ${ }^{18}$ For my purposes here, I do not need to go into the detail of the argument, which consists in finding drawbacks in two different ways of spelling out such a conception. Independently of detail, Sellars is surely right to find the conception - "the notion that acts of the intellect are intrinsically alike regardless of what they are about" _ 19 utterly unprepossessing.

Having arrived at this conclusion, with more detail than I have rehearsed, Sellars writes:

But what is the alternative? In general terms it is to hold that acts of the intellect differ intrinsically qua acts in a way which systematically corresponds to what they are about, i.e. their subject-matter. ${ }^{20}$

This is a version of his standard view of meaning and aboutness. Acts of the intellect, mental acts, differ intrinsically in their semantic properties, which, in the Thomistic image, are the semantic properties of the intellectual words that are actualized in them; and the semantic properties systematically correspond to what the acts are about by way of the reflection, into what semantical statements say, of relations there ought to be whose relata include what the acts are about.

This has the form of an argument to establish Sellars's doctrine that aboutness is non-relational by eliminating any alternative. But the argument is vitiated by the blind spot for Tarski. Sellars's argument assumes that, if someone wants to say intellectual acts differ, not in a way that systematically corresponds to what they are about, but in being about what they are about, she will admit to supposing that intellectual acts do not differ intrinsically at
18 Ibid., p. 41.
19 Ibid., p. 42.
20 Ibid., p. 43. 
all. He assumes that a relational difference between a pair of intellectual acts could only be an extrinsic difference. And a proper appreciation of Tarski gives the lie to this assumption. It is Sellars's own reasonable thought - the basis on which he rejects the only competing possibility he considers - that a difference in intentional directedness between a pair of intellectual acts is an intrinsic difference between them. It is Sellars's own reasonable thought that we can frame a difference in intentional directedness between a pair of intellectual acts as a difference in the semantics of the intellectual words that are actualized in them. If we conceive the semantics of intellectual words in a Tarskian way, as involving relations between elements in the intellectual order and elements in the real order, with the relations fraught with "oughts" ultimately reflecting the demands of the constitutive ideal of rationality, that yields, untouched by Sellars's argument, a conception according to which intellectual acts, mental acts, can differ intrinsically in being related - semantically in the extended sense opened up by the Thomistic image - to different things.

We open this possibility by exploiting the conception of the semantical that Davidson, exploiting Tarski, has made available. I want to end by mentioning an implication for the idea of the subjective. Under the label "the Myth of the Subjective", Davidson has attacked a conception of the subjective whose effect is to make our access to the objective, and our understanding of ourselves, problematic in the familiar ways that characterize philosophy in the Cartesian vein. ${ }^{21}$ Of course I have no wish to defend the target of that attack. However, it seems to me to be a shame

${ }^{21}$ See "The Myth of the Subjective", in Michael Krausz (ed.), Relativism: Interpretation and Confrontation, Notre Dame University Press, Notre Dame, 1989, pp. 159-172. 
to concede the very idea of the subjective to philosophy in that vein. A Davidsonian understanding of semantics allows us to take it that mental acts are intrinsically characterized by being semantically related -in the extended sense of "semantically" - to elements in the extra-mental order. On that basis we can begin to reclaim an idea of the subjective from the philosophical distortions that enter into the Myth. In the first part of this paper, I urged that the point of invoking the constitutive ideal of rationality, in situating the idea of the mental, is to dismantle Cartesian assumptions. This exploitation of a relational conception of intentionality would go further in that direction.

Recibido: 18 de enero de 1998 